\title{
Editorial
}

\section{Ecologia dos meios e abertura dos fins:}

\section{Comunicação, temporalidades e narrativas \\ Editorial}

\section{Media ecology and opening to endings:}

\section{Communication, temporalities and narratives}

\section{Por Gustavo Chataignier e Alexandre Carauta}

Há 20 anos nascia a Alceu. Inspirada no jornalista Alceu Amoroso Lima, um dos fundadores da PUC-Rio, abraçava o desafio de triangular comunicação, cultura e política. Os 12 textos da edição comemorativa revigoram esse compromisso com o pluralismo e a densidade científica. Sinalizam também uma permanente janela à renovação. Incorporada ao Programa de PósGraduação do Departamento de Comunicação Social, a revista inaugura o padrão bilíngue e o seu novo ambiente digital, com mais funcionalidades e informações. Um convite extra para se embarcar na Alceu 40.

O dossiê "Narrativas midiáticas: tempo presente e história cultural" conduz o eixo teórico da edição. Congrega seis pesquisas associadas a linguagens e experiências narrativas sob diferentes contextos, abordagens, perspectivas. A pluralidade, estendida aos demais artigos da edição, fortalece o diálogo da comunicação com outras áreas do conhecimento. Nele caminha a revista desde a largada, em julho de 2000.

O compasso transdisciplinar ganha fôlego nas seções dedicadas a resenhas de livros acadêmicos e entrevistas. As iniciativas ampliam a abertura à produção intelectual e ao confronto de ideais iniciada lá se vão duas décadas. 


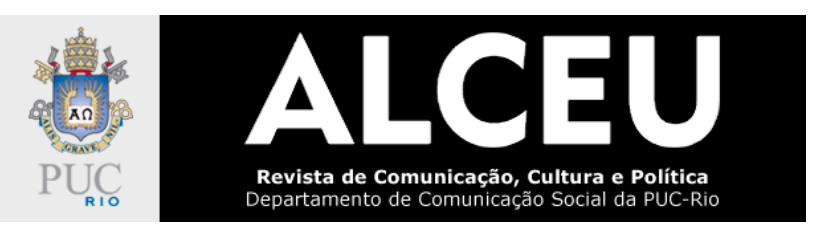

Sob o gabarito de editores como Fernando Sá e Felipe Gomberg, a Alceu consolidou reflexões referentes a conceitos, metodologias e questões éticas do campo da comunicação. Incrementou o debate em torno de suas imbricações culturais, socioeconômicas, políticas, filosóficas (Convidado a participar da edição comemorativa, Fernando relembra passagens dessa trajetória em um texto adjacente.)

Digital desde 2004, a revista alinha-se às mudanças tecnológicas e às novas dinâmicas comunicativas. Assim evidencia a remodelagem da área on-line. Em consonância com as diretrizes da Capes, a nova interface facilita a vida de leitores, autores, pareceristas e editores. Favorece, por exemplo, a indexação de pesquisas e a transparência de dados. Logo, adequa-se melhor a padrões internacionais, exigidos pelas agências de fomento.

As novidades realçam o repertório desta edição especial. Diversidade e consistência científica revelam-se já no dossiê de abertura, cujo tema foi sugerido pelo antropólogo Everardo Rocha, professor titular da PUC-Rio e do Departamento de Comunicação Social, um dos artífices do Programa de Pós-Graduação em Comunicação da universidade. O dossiê "Narrativas midiáticas: tempo presente e história cultural" busca aprofundar o estudo das formas narrativas como agentes da construção de subjetividades, representações, sistemas de valores, rituais, práticas de consumo.

Ao encontro desse propósito, Adriana Barsotti analisa a articulação entre memória e esquecimento acionados a partir da leitura de primeiras páginas jornalísticas nos suportes impresso e on-line. Neste primeiro artigo do dossiê, "Memória e esquecimento no jornalismo: do papel à desmaterialização digital", Barsotti também reflete sobre os efeitos dos fluxos desmaterializados das mídias digitais no jornalismo - tradicional formador da memória social compartilhada. Para fundamentar as análises, a pesquisadora entrevistou dez editores de primeiras páginas nos meios impresso e on-line.

A comunicação contemporânea também é o ponto de partida de Ana Taís Martins, ao enveredar-se por uma questão original: a eficácia simbólica das transposições do mito na mídia, associando-o a schèmes, arquétipos, imagens. Como indicado já no título, "Narrativas na comunicação: a persistência mitogênica", o segundo artigo do dossiê se debruça sobre as mudanças das narrativas míticas no âmbito das dinâmicas comunicativas contemporâneas. 
Alinhada à Teoria Geral do Imaginário, principalmente por meio de G. Durand e J.J. Wunenburger, a autora descreve as mutações necessárias a um dado sermo mythicus - narrativa fundamental que orienta a experiência humana em todas as épocas e culturas - para sobreviver nas instâncias da consciência social. Ana Taís avalia que o simbólico permanece vivo nas narrativas míticas enrijecidas do imaginário coletivo, e arremata: o papel do mitólogo das comunicações é desocultar os sentidos reprimidos do mito.

Já Ângela Marques e Francine Altheman discutem o papel da experiência estética para a emancipação política. Elas atualizam o debate tomando por pano de fundo o movimento secundarista que ocupou as ruas e as escolas de São Paulo em 2015. O terceiro texto do dossiê, "Figurações e potencialidade estética dos arranjos comunicativos nas cenas de insurgência secundarista", traça uma reflexão acerca da influência das criações observadas nos protestos estudantis - performances, cartazes, bricolagens, intervenções - sobre a formação política. As autoras partem do diálogo entre Foucault, Rancière e Deleuze em torno da constituição do sujeito político nas resistências para mergulharem na fabulação estética da cena insurgente, e nos arranjos disposicionais que a compõem.

Na sequência, Míriam Cristina Carlos Silva, Tadeu Rodrigues luama e Vanessa Heidemann apresentam, em "Eu fui o que tu és, e tu serás o que sou: um olhar fenomenológico das narrativas em epitáfios", o resultado da incursão por epitáfios de um cemitério em Sorocaba, no interior paulista. A pesquisa partiu da premissa de que epitáfios são uma tentativa de narrativizar, de forma concisa, as experiências vividas. Amparados no diagnóstico de Baitello Junior sobre a condição sedada do humano, barreira à construção e ao registro das memórias, os autores buscaram identificar Zonas Autônomas Temporárias, ou seja, brechas na lógica da sedação. Diferentemente do imaginado, as encontradas expuseram o abandono dos mortos e a repetição de frases feitas.

Pontes também não faltam nas imbricações entre os meios on-line e o marketing atualizadas por Taís Steffenello Ghisleni e Graziela Frainer Knoll em “Estratégias de comunicação na ambiência digital: mapeamento do quadro conceitual". Em meio ao debate sobre os impactos das novas dinâmicas interativas na publicidade, as autoras partem de uma pesquisa exploratória para identificar mecanismos de alinhamento da comunicação e do marketing às especificidades dos ambientes digitais. 


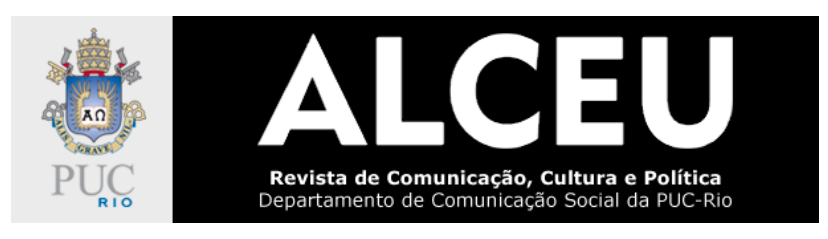

"Mapas fotográficos do Google" fecha o primeiro volume do dossiê (o segundo está programado para a edição 41). Ao abordar o Google Maps e os demais softwares acoplados ao serviço (Google Earth, Google Moon, Google Mars e Google Street View), Grécia Falcão ilumina o relevo da fotografia aérea na ciência cartográfica. Pontua a importância da técnica fotográfica para a criação de uma narrativa visual primada pela verossimilhança, ou seja, mais fiel à representação possível do espaço. Mais do que assinalar a conveniência dessas narrativas à documentação, análise e gestão das informações geográficas, a autora investiga o sentido comunicacional dos mapas do Google a partir da análise de duas séries fotográficas criadas por Mishka Henner. As estratégias de apropriação, produção e montagem operacionalizadas pelo artista belga parecem multiplicar as formas de comunicação das imagens, variando o sentido do conjunto de fotografiasmapa geradas pelo Google.

O sétimo artigo da edição comemorativa da Alceu é um presente de Néstor Ponce. Radicado desde 1979 na França, onde leciona Literatura na Universidade Rennes II, o escritor argentino evoca, em "Mafalda. Un universo infantil en medio de la masculinidad", o painel de personagens criado por Quino. Com a habitual acuidade, Néstor Ponce analisa a relevância das tiras protagonizadas pela questionadora Mafalda, publicadas entre 1964 e 1973, para a literatura juvenil argentina. Ao retratar a atualidade desse ícone dos quadrinhos, o autor dedica um olhar especial à relação de gênero de Mafalda com os adultos (homens e mulheres, mas com ênfase nas atitudes masculinas) e com as crianças.

Dos quadrinhos para o cinema. Em "Linguagem e conhecimento por imagens: conversações entre Benjamin, Bakhtin e Pasolini”, Danilo Marques da Silva Godinho e Cintia de Souza Carvalho debatem a utilidade da videogravação ao conhecimento científico. O trilho dessa análise articula reflexões sobre linguagem desenvolvidas por Walter Benjamin e Mikhail Bakhtin com a análise da obra teórica e cinematográfica de Pier Paolo Pasolini. Os autores constatam que o universo do cinema oferece subsídios para o uso da imagem técnica na pesquisa em ciências humanas, ensejando narrativas imagéticas.

Entrelaces não menos interessantes são observados em "A crítica do narrador intelectual pingente: Lima Barreto evocado por João Antônio". Cláudio Rodrigues Coração examina manifestações expostas pelo narrador intelectual pingente, a partir de textos literários e jornalísticos de Lima Barreto. O diagnóstico ecoa na obra do também escritor e jornalista João Antônio, 


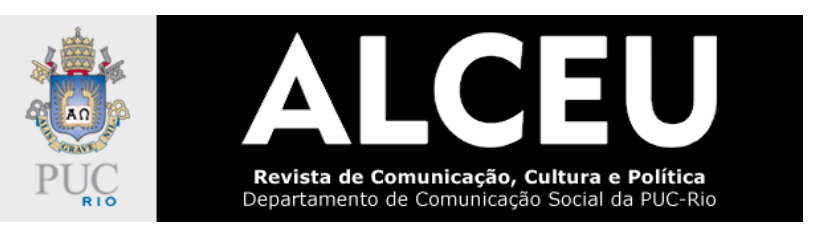

especialmente em Calvário e porres do pingente Afonso Henriques de Lima Barreto (1977). Coração entrelaça tais textos por meio da descrição, discussão e análise da crítica firmada como elemento decisivo aos propósitos do narrador pingente. Para isso, depura aspectos de mediação e valores culturais no diálogo entre os dois autores. Percurso no qual o pesquisador se cerca de referenciais teóricos condizentes com a reflexão da crítica como fenômeno intelectual, comunicacional e artístico.

"And the winner is... As premiações e o empreendedor do sucesso quantificado", de Gisela Castro e Carolina Fabris, investiga como o neoliberalismo se converteu contemporaneamente em uma verdadeira máquina de subjetivação, na medida em que cria ritos e instituições com o papel de legitimar sua própria eficácia simbólica. A quantificação de desempenhos e a exaltação da competição entre indivíduos transparecem em prêmios brasileiros, como o Prêmio Empreendedor do Ano e o Prêmio Empreendedor de Sucesso.

Perspectiva semelhante habita " 50 anos do Jornal Nacional: estratégias e desafios no ambiente convergente". Beatriz Becker reflete, nesse artigo, sobre mudanças do telejornal diante da produção, circulação e do consumo de conteúdos noticiosos reconfigurados pelas mídias digitais. Afinada ao modelo interpretativo da Análise Televisual Convergente (ATC), a pesquisadora estuda 13 edições do JN veiculadas em 2019. Mais de 10 horas de notícias em áudio e vídeo estruturam a observação de cinco dimensões dos processos comunicativos de telejornais e programas televisivos: os sentidos do texto, as singularidades das ambiências (e/ou dispositivos), a circulação, a produção e as interações das audiências. A investigação aponta uma reorganização discursiva da linha editorial do noticiário, nomeada de "humanismo solidário", para atrair grandes audiências no atual contexto político do país.

Étienne Balibar arremata a Alceu 40, na seção dedicada a traduções, com um de seus textos mais recentes. Em "Marx: tudo está por ser refeito" (tradução de Gustavo Chataignier), o filósofo francês faz um balanço daquilo que permanece inabalável no campo gravitacional em torno de Marx e daquilo que demanda uma refundação, para oxigenar as frentes intelectuais e científicas voltadas para refletir alternativas ao capitalismo. O texto mescla episódios biográficos - tanto a militância quanto os anos de formação na École Normale Supérieure - com uma reflexão acerca de grandes encontros intelectuais, formadores do, por assim dizer, "sujeito Balibar": o marxismo enquanto filosofia rigorosa, no grupo de Louis Althusser; o diálogo com Immanuel Wallerstein sobre 
o "capitalismo histórico", cuja compreensão e logicidade empurram para além das amarras de vícios abstratos; na maturidade, o feminismo teórico, apresentando formas de dominação anteriores ao capitalismo e com ele se conjugando (como Silvia Federici e a necessária problematização do trabalho doméstico); o operaísmo italiano e os escritos de Mario Tronti acentuam a questão do agonismo político em sobreposição aos mecanismos de reprodução social e de produção de riqueza. Um pensamento do comum em meio a diferenças antropológicas é o horizonte que guia a renovado exercício de crítica.

Os 12 textos desta edição comemorativa acentuam o compromisso com a pluralidade, a transdisciplinaridade e a profundidade firmado há 20 anos. Ele se distende ainda mais com a internacionalização da Alceu, sinalizada na estreia do padrão bilíngue, e com o novo ambiente digital. Estreita-se, assim, o diálogo da comunicação com outros campos do saber, assim como a articulação entre perspectivas locais e globais.

Boa leitura e até a próxima edição!

Gustavo Chataignier

Editor da Revista Alceu

Professor do Departamento de Comunicação da PUC-Rio Pesquisador associado ao Departamento de Filosofia da Universidade de Paris 8 ORCID: https://orcid.org/0000-0002-1846-0369

Alexandre Carauta Editor da Revista Alceu Professor do Departamento de Comunicação da PUC-Rio Doutor em Comunicação pela PUC-Rio ORCID: https://orcid.org/0000-0002-3607-8710 